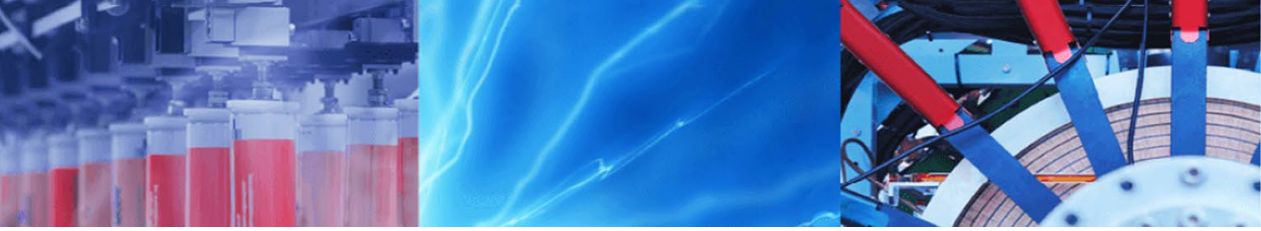

Review Paper

\title{
Correlation between theoretical and experimental hardness, elastic modulus of discarded aluminium piston reinforced with zirconium diboride and snail shells
}

\author{
E. O. Olawuni ${ }^{1}$ M. O. Durowoju ${ }^{1} \cdot$ T. B. Asafa ${ }^{1}$
}

Received: 3 December 2019 / Accepted: 17 February 2020 / Published online: 22 February 2020

(c) Springer Nature Switzerland AG 2020

\begin{abstract}
Aluminium metal matrix composites have gained a lot of attention because of their outstanding properties making them useful for aerospace, automobile and marine applications. Composites are replacing metals as structural materials, and a detailed study of the relationship between hardness and Young's modulus becomes essential. In this paper, the correlation between hardness and elastic modulus of discarded aluminum pistons reinforced with zirconium diboride and snail shells is presented. The theoretical hardness was determined from the ratio of indentation hardness to indentation modulus while elastic modulus was evaluated based on composite equation. The results indicated that hardness and elastic modulus increased with the weight percentage of the composites while the resistance to plastic deformation $\mathrm{H}^{3} /$ $\mathrm{E}^{2}$ increased with $\mathrm{H}$. The wide discrepancy between the theoretical and experimental Young's modulus is attributed to the fact that theoretical elastic moduli were obtained from perfect/single crystal materials while experimental values are obtained from polycrystalline/imperfect crystals. The calculated Young's moduli obtained through mixture rule range from 64 to $92 \mathrm{GPa}$ which are higher than $69 \mathrm{GPa}$ of aluminium alloy. It is therefore evident that the composite materials can be used for engineering applications.
\end{abstract}

Keywords Mechanical properties · Casting · Aluminum composite $\cdot$ Snail shells · Zirconium diboride

\section{Introduction}

Composite materials have drawn a lot of attention because of the unique properties they offered when compared with polymer, metals and alloys. Ceramics reinforced matrix composites are known for their high strength to weight ratio, superior tribological properties and corrosion resistance behaviour making them good replacements for monolithic alloys in the field of automobile, marine and aviation engineering [1-3]. Aluminium metal matrix composites are very attractive for variety of applications.
Silicon carbide and aluminium oxide were mainly used as reinforcements in early decade but attention was later shifted to fly ash silicon oxide, titanium oxide, aluminium nitride, silicon nitride, titanium boride and zirconium diboride as different reinforcements [4-6]. The strength and behaviour of composite materials depend upon type of matrix and reinforcing material, amount of reinforcement, composition, grain size, microstructure and fabrication process [7].

Zirconium diboride is known for its high thermal stability/melting point. It retains its mechanical strength at

Electronic supplementary material The online version of this article (https://doi.org/10.1007/s42452-020-2272-8) contains supplementary material, which is available to authorized users.

E. O. Olawuni, olawunioladapo@yahoo.ca; M. O. Durowoju, modurowoju@lautech.edu.ng; T. B. Asafa, tbasafa@lautech.edu.ng| ${ }^{1}$ Department of Mechanical Engineering, Ladoke Akintola University of Technology, P.M.B. 4000, Ogbomoso, Nigeria. 
high temperature and has a special bonding system which is responsible for its excellent physicochemical properties [8]. Zirconium diboride has three bonding systems. The first being the Boron-Boron bonding system which is covalent in nature and it increases the stiffness of the overall structure resulting in high melting temperature, hardness, strength and chemical stability of transition diboride. The second of bonding is M-B which is also covalent in nature with a limited amount $\left[8 \%\right.$ for $\mathrm{ZRB}_{2}$ ] of ionic character $[9,10]$. The last type of bond in the $\mathrm{MB}_{2}$ structure is metal -metal bonding. This environment gives rise to metallic bonding and contributes to the high electrical and thermal conductivities of diboride $[10,11]$. Jato et al. [12] reported that snail shells can be used as a low cost reinforcement in metal matrix composites because of its high carbonaceous content $(97.5 \mathrm{wt} \%$ Calcium carbonate and $2.5 \mathrm{wt} \%$ of other elements like Calcium phosphate, Calcium silicate, Magnesium oxide, Iron oxide, Manganese oxide, Sodium, and Potassium) and modulus of elasticity.

Indentation experiments have been performed for measurement of hardness. A significant improvement on indentation equipment keeps increasing in order to improve measurement accuracy [13-18]. Hardness is reported as complex parameter which involves elasticity and plasticity governed by intrinsic properties such as bond strength, cohesive energy and crystal structure [19]. A super hard material has a high bulk modulus, shear modulus and shear strength. However, hardness cannot be quantitatively described by shear and bulk moduli but can be used to estimate the elastic modulus of composites with various weight percentages (wt\%) of composites [19]. Labonte et al. [18] reported that indentation hardness is a hybrid measure of a material resistance to irreversible and reversible deformation, and a change in indentation modulus will also affect indentation hardness.

Elastic modulus quantifies the resistance of a material to (reversible) deformation, while the ratio of hardness to elastic modulus is important in both tribology and fracture mechanics. True hardness (theoretical hardness) is a measure of plasticity and Young's modulus is a measure of elasticity [20]. The theoretical background and interpretation of parameters have been measured through indentations from various researches on traditional engineering [18]. It has been reported in many literatures that indentation modulus, $E_{i}$ is equal to the plain strain modulus, $E^{i}$.

This paper presents the comparison of experimental and theoretical values of aluminium piston reinforced with zirconium diboride and snail shells. It also meant to determine and compare; (1) the correlation between hardness and elastic modulus using indentation modulus, $\mathrm{E}_{\mathrm{i}}$ and indentation hardness $\mathrm{H}_{\mathrm{i}}$ as reported by Labonte et al. [18] in biological materials, (2) the resistance of the piston material to plastic deformation, (3) variation of weight percentage (wt\%) of composites with hardness and modulus.

The influence of alloying elements on piston performance was studied using D-optimal technique (DOT), which is a component of mixture design of experiment (particle reinforcement aluminium matrix composite). Furthermore, the effects of zirconium diboride and snail shells were investigated on discarded aluminium pistons using stir cast technique due to its simplicity and cost effectiveness. The pistons were recast, machined and subjected to tensile and hardness tests. Previous studies have been conducted on discarded pistons collected from different manufacturer and the piston materials were subjected to tensile strength on tensiometer tensile machine [21]. The best samples were selected using high tensile strength and further characterized for hardness (brinnel), fatigue, impact, corrosion, density, SEM and XRD.

To ensure uniformity, we collected discarded pistons manufactured by BAJAJ extra NIKKO piston (Japan standard technology model BAJAJ 100 size standard). No literature has reported the correlation between theoretical, experimental hardness and elastic modulus as related to the composition of material of discarded aluminium piston reinforced with zirconium diboride and snail shells. The addition of zirconium diboride and snail shells reinforced particle will not only improve the mechanical properties at room temperature but also at high temperature and improve the factor of safety compared to unreinforced alloy material because of the presence of reinforcement in the matrix alloy increases the yield strength of a material [22].

\section{Materials and methods}

\subsection{Material preparation}

The method used in this study is reported in literature [21] on discarded aluminum pistons that were collected from different auto-mechanic workshops in Ogbomoso, SouthWest Nigeria. The pistons were cleaned from dirt by means of organic solvent and liquid detergent. The piston scraps were melted in an electric furnace and the molten alloy was obtained as ingot [21]. The compositions of the as-cast samples were also analyzed using Energy Dispersive X-ray fluorescence (EDXRF) Mini Pal 4, Malvern Pan Analytical, Netherlands. African giant snail shells (Achatina achatina) were collected from a dump site in Ogbomoso. The snail shells of particle size $150 \mu \mathrm{m}$ were prepared following the method described elsewhere [12, 21]. Zirconium diboride of particle size $45 \mu \mathrm{m}$ were purchased from foreign market, and were used as reinforcing materials to reduce high temperature fatigue because of its ability to retain mechanical 
Table 1 Experimental runs obtained from D-optimal technique and control sample

\begin{tabular}{llllc}
\hline $\begin{array}{l}\text { Experi- } \\
\text { mental } \\
\text { run }\end{array}$ & Samples & $\begin{array}{l}\text { Discarded } \\
\text { piston } \\
\text { (wt\%) }\end{array}$ & $\begin{array}{l}\text { Zirconium } \\
\text { diboride } \\
\text { (wt\%) }\end{array}$ & $\begin{array}{l}\text { Snail shells } \\
\text { (wt } \%)\end{array}$ \\
\hline 1 & DPZRB $_{2}$ SS1 & 80.00 & 10.00 & 10.00 \\
2 & DPZRB $_{2}$ SS2 & 80.00 & 20.00 & 0.00 \\
3 & DPZRB $_{2}$ SS3 & 72.50 & 22.50 & 5.00 \\
4 & DPZRB $_{2}$ SS4 & 70.00 & 10.00 & 20.00 \\
5 & DPZRB $_{2} S 55$ & 75.00 & 15.00 & 10.00 \\
6 & DPZRB $_{2}$ SS6 & 80.00 & 0.00 & 20.00 \\
7 & DPZRB $_{2}$ SS7 & 75.00 & 5.00 & 20.00 \\
8 & DPZRB $_{2}$ SS8 & 70.00 & 30.00 & 0.00 \\
9 & DPZRB $_{2}$ SS9 & 70.00 & 20.00 & 10.00 \\
10 & DPZRB $_{2}$ SS10 & 75.00 & 10.00 & 15.00 \\
\hline
\end{tabular}

strength at high temperature. The melting process was carried out in an oil fired furnace. All the discarded aluminium pistons collected were melted inside a crucible pot in the furnace, where the mould was pre-heated at a temperature of $660^{\circ} \mathrm{C}$ to avoid sudden solidification of the cast samples.

Snail shell particles were added to zirconium diboride and later poured into discarded piston at different wt\%. As shown in Table 1, at melting temperature of $700 \pm 5^{\circ} \mathrm{C}$ and stirred continuously for $5 \mathrm{~min}$. Meanwhile, the temperature of all the mixture was raised to $1300^{\circ} \mathrm{C}$ for homogeneity and dross was removed prior to pouring [21]. The procedure was also used for all the samples with varying $w t \%$.

\subsection{Sample preparation}

Rod samples (15 mm diameter and $300 \mathrm{~mm}$ long) were cast as ingot in sand mould. The samples were then cleaned and inspected for feasible defects. It was then machined into different specification as required by each test.

\subsection{Experimental design and optimization}

The influences of alloying element on piston performance were studied using D-optimal technique (DOT), which is a component of mixture design of experiment (particle reinforcement aluminum matrix composite). The modified samples involved combinations of discarded aluminum piston (DP), zirconium diboride ( $\mathrm{ZRB}_{2}$ ) and snail shells (SS) comprised of 10 experimental runs. The snail shells compositions were varied between 0 and $20 \mathrm{wt} \%$, while zirconium diboride compositions were in the range $0-30 \mathrm{wt} \%$ as shown in Table 1 [10]. The reinforcements were added to molten discarded aluminum piston, stirred rigorously to ensure uniformity, and then poured into a mould [10].

\subsection{Mechanical testing}

Hardness and tensile tests were carried out on the samples. Hardness test was performed on Rockwell hardness machine of HR15N with diamond indenter. The samples were cleaned by removing the dirt/dust and grease. Each sample was then placed securely on the anvil and the load lever adjusted to the right position. The sample was placed under preliminary load by load selector. Then, a diamond indenter of $1.588 \mathrm{~mm}$ diameter was pressed into the surface gradually and automatically applied. Then Rockwell hardness value is calculated. The data reported were measured at least ten times and average of four closest results were selected and taken as the hardness results.

A universal testing machine (UTM) was used for measuring tensile properties like tensile strength and modulus of elasticity was evaluated. American society of testing material (ASTM E8) standard was followed as shown in Fig. 1.

\subsection{Theoretical Young's modulus calculation}

The theoretical Young's modulus was evaluated according to Callister [23] which reported that the rule of mixture equation predicts that elastic modulus should fall between an upper bound $(\mathrm{u})$ and lower bound $(\mathrm{L})$. The modulus of elasticity for snail shells, aluminium, and zirconium diboride are 50,69 and 450 GPa respectively [24-26].

$E_{c}(u)=E_{m} V_{m}+E_{z} V_{z}+E_{s} V_{s}$

$E_{C}(L)=\frac{E_{m} E_{z} E_{s}}{V_{m} E_{z} E_{s}+V_{z} E_{m} E_{s}+V_{s} E_{m} E_{z}}$

$\frac{1}{E_{c}}=\frac{V_{m}}{E_{m}}+\frac{V_{z}}{E_{z}}+\frac{V_{s}}{E_{s}}$

where $\mathrm{E}, \mathrm{V}, \mathrm{C}, \mathrm{M}, \mathrm{Z}$ and $\mathrm{S}$ denote elastic modulus, wt $\%$ of mixture, composite, matrix, zirconium, and snail shells [23].

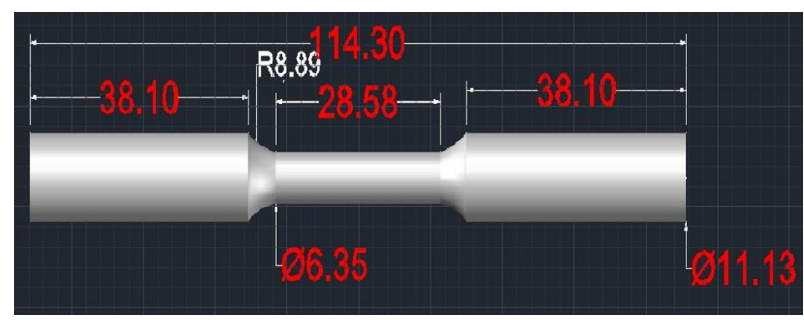

Fig. 1 Dimension of tensile sample 


\subsection{Correlation between theoretical hardness and theoretical Young's modulus}

According to Labonte et al. [18], true resistance to plastic deformation, $\mathrm{H}$, depends on the ratio between indentation hardness to indentation modulus. True hardness (theoretical hardness) is estimated with Eq. 5.

$\mathrm{H}_{\mathrm{i}}=0.046 \mathrm{E}_{\mathrm{i}}^{1.03}$

$\mathrm{H}=\frac{H_{i}}{\left(1-\frac{\sqrt{H_{i}}}{E_{i}} * \sqrt{2 \operatorname{Tan}(\beta)}\right)^{2}}$

$H_{i}, H, E_{i}, \beta$, connote indentation hardness, true hardness, indentation modulus, equivalent to cone angle of indenter; $19.7^{\circ}[15,18]$.

\subsection{Further characterization}

Scanning electron microscopy (SEM) was carried out on Phenom Prox Phenomworld (Eindhoven, Netherland). The X-ray Diffraction (XRD) machine (PAN analytical BV and Netherland operated) with data tube current of $40 \mathrm{~mA}$ and tension of 45 VA was used for XRD analysis. The $d$-spacing of each peak was then obtained by using Bragg equation. The peaks obtained from this analysis were matched with the minerals phases of the $d$ (Theta in deg) attached to the XRD processing software (XPert Highscore Plus which is also from Panalytical) was used.

\section{Results and discussion}

\subsection{Tensile strength and rockwell hardness value}

The mechanical properties of samples made from discarded piston, zirconium diboride and snail shells are summarized in Table 2. Sample DPZRB ${ }_{2}$ SS2 (80 wt $\%$ of $\mathrm{DP}, 20 \mathrm{wt} \%$ of $Z \mathrm{ZB}_{2}$ and $0 \mathrm{wt} \%$ of SS) has ultimate tensile strength, modulus of resilience and strain rate of 159.27 $\mathrm{MPa}, 54.95 \mathrm{GPa}$ and $0.69 \%$ respectively. It was also observed that sample DPZRB ${ }_{2} \mathrm{SS} 3$ ( $72.5 \mathrm{wt} \%$ of DP, $22.5 \mathrm{wt} \%$ of $Z \mathrm{ZRB}_{2}$ and $5 \mathrm{wt} \%$ of SS) has the highest ultimate tensile strength, modulus of resilience and strain rate of $161.15 \mathrm{MPa}, 56.40 \mathrm{GPa}$ and $0.70 \%$, respectively.

From Table 2, it is evident that the addition of snail shells increases the modulus of resilience; when no snail shells were added in DPZRB ${ }_{2} \mathrm{SS} 2$ a lower modulus of resilience was given compared to when $5 \mathrm{wt} \%$ of snail shells was added in $\mathrm{DPZRB}_{2} \mathrm{SS} 3$. In addition, considering sample DPZRB ${ }_{2} \mathrm{SS} 6$ ( $80 \mathrm{wt} \%$ of DP, $0 \mathrm{wt} \%$ of $Z \mathrm{ZRB}_{2}$ and $20 \mathrm{wt} \%$

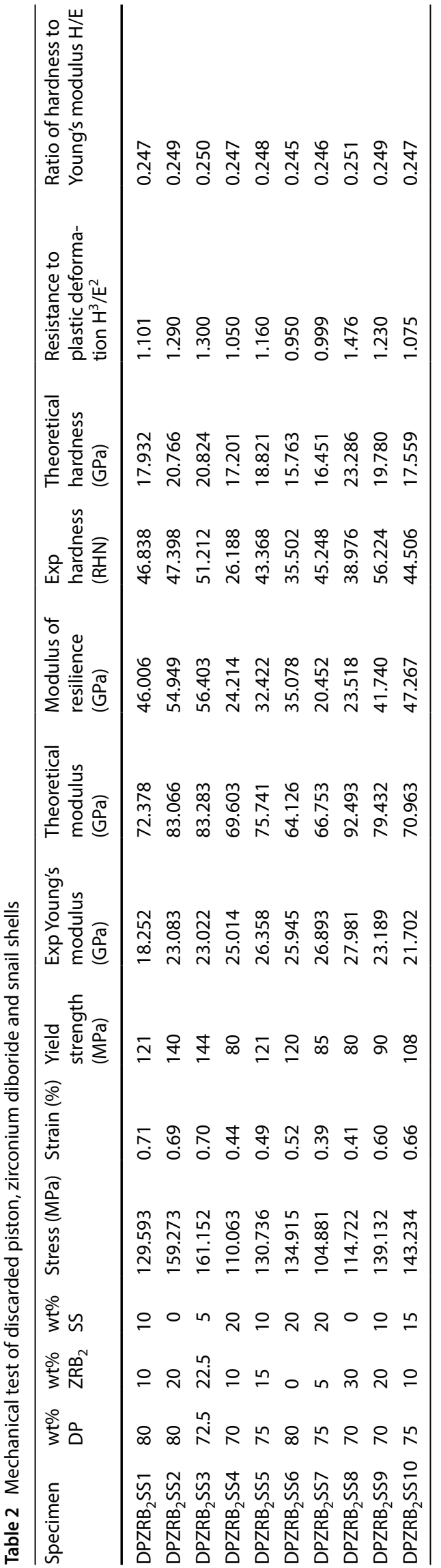


of SS) when $20 \mathrm{wt} \%$ of snail shells were added without zirconium diboride, the modulus of resilience was 35.0 GPa and it is higher than DPZRB ${ }_{2} \mathrm{SS} 8$ (70 wt\% of DP, 30 wt $\%$ of $Z R B_{2}$ and 0 wt $\%$ of $S S$ ) with modulus of resilience of $23.5 \mathrm{GPa}$ which contain $0 \mathrm{wt} \%$ of snail shells.

Shen et al. [27] concluded that the tensile strength of the composite was determined by the relationship between the particle strength and particle matrix interface strength. Shen et al. [27] also reported that high strength particle/matrix interface can transfer maximum load to the particle until the particle fracture occurs. When the interface strength is greater than the particle strength, particle fracture happens under tensile loading. When the interface strength is lower than the particle strength, particle pull out is the predominant mode of the particle failure [27].

Increase in zirconium diboride content with increase in the ultimate tensile strength and the reduction in percentage ductility were observed in samples (DPZRB $2 \mathrm{SS}$, 2 and 3) from Table 2 as reported in the literature [28]. This may be attributed to the distribution of zirconium diboride particle in the matrix which is related to the solidification process of the matrix alloy. The density difference between the melt and a particle is over $3.5 \mathrm{~g} / \mathrm{cm}^{3}$ [28]. Dinaharan et al. [28] reported that the wetting effect between the particle and the melt retards the movement of the zirconium diboride particle which can be distributed in the melt for a long time. Zirconium diboride acts as load bearing element and takes maximum load for plastic deformation by increasing the hardness, it allows material to flow without undergoing deformation but when it exceeds critical value, it causes fracture without further deformation [28].

The modulus of these composites increased with increasing snail shell particles which suggest that snail shell powder was reported to be effective in distributing the applied stress over a large volume at the base of the notch, and which helped to prevent propagation of cracks by carrying large part of the load in the area under crack [29].

Snail shells in the matrix prevented movement in the area around each particle, contributing to an overall increase in the modulus, which supports the work of Hussein et al. [30]. Atuanya et al. [31] also reported that, the increase in the snail shells filled composite is attributed to an increase in rigidity of recycled low density polyethylene (RLDPE) related to restriction of the mobility in RLDPE which was due to the presence of snail shells particle. The distribution of snail shells particle is influenced by good wettability of the snail shell particle by the molten metal and good interfacial bonding between particles and matrix material [31].
The increase the tensile strength due to the absence of snail shells and presence of zirconium diboride in samples $\mathrm{DPZRB}_{2} \mathrm{SS} 2$ from Table 2 is as a result of the mechanical strength of zirconium diboride [8-10]. Also, hybrid composite were used in some samples like (DPZRB $\left.{ }_{2} \mathrm{SS} 3\right)$, the increase in its modulus of resilience can be attributed to the presence of zirconium diboride (good mechanical strength) and snail shells. Snail shells have good wettability which promotes good bonding between the matrix and reinforcement [31] and consequent enhancement of the ultimate tensile strength [32].

It is concluded that, the increase in snail shells increases the mechanical properties of a piston material which also compliment the work of Asafa et al. [32] that tensile strength increased with increase in weight percentage ( $w t \%)$ of snail shell particles and the increase can be attributed to uniform distribution of snail shell particles in the ductile aluminium matrix as reported by Aigbodion and Hassan [33]. However, it can also be shown in Table 2 that sample DPZRB ${ }_{2} \mathrm{SS} 1$ ( $80 \mathrm{wt} \%$ of DP, $10 \mathrm{wt} \%$ of $\mathrm{ZRB}_{2}$ and $10 \mathrm{wt} \%$ of SS) has lower tensile strength than $\mathrm{DPZRB}_{2} \mathrm{SS} 3$ (72.5 wt $\%$ of DP, $22.5 \mathrm{wt} \%$ of $\mathrm{ZRB}_{2}$ and $5 \mathrm{wt} \%$ of $\mathrm{SS})$. This decrease in tensile strength can be linked to the size, shape and distribution of the pores within the microstructure [32, 34].

The average Rockwell hardness values are also shown in Table 2 with standard deviation of 4.03. Sample DPZRB 2 SS9 has the highest hardness value and Young's modulus of 56.22 RHN and 23.19 GPa compared to sample DPZRB ${ }_{2} \mathrm{SS}_{3}$ with hardness value and Young's modulus of 51.21 RHN and $23.02 \mathrm{GPa}$, respectively. Although, there is a little difference in their hardness value and the difference in their Young's modulus is insignificant. The optimal hardness result obtained in this study is also higher than the maximum hardness values of $50.8 \mathrm{BHN}$ and $44.3 \mathrm{HRF}$ obtained from related studies because of the properties of the reinforcements (zirconium diboride and snail shells) used $[32,34]$. Zirconium diboride, being a ceramics material, is known for high strength to weight ratio, high hardness and superb thermal shock resistance $[8,9,12]$.

Snail shells particle increase hardness because of the hard phase of the snail shells particle. The hardness of snail shells particle is due to the presence of $\mathrm{CaCO}_{3}, \mathrm{C}$ and $\mathrm{SiO}_{2}$ of the chemical made up of the particle as reported by Patricio et al. [12,35]. Zirconium diboride particles may also increase the dislocation density; it can create more resistance to plastic deformation resulting in enhanced hardness [28]. Figure 2 presents the stress-strain graph of discarded piston reinforced with zirconium diboride and snail shells. At strain rate of $0.13 \%$, all the sample were observed to be undergoing a minor deformation and they tend to rise to different yield point before they tend to fail. 


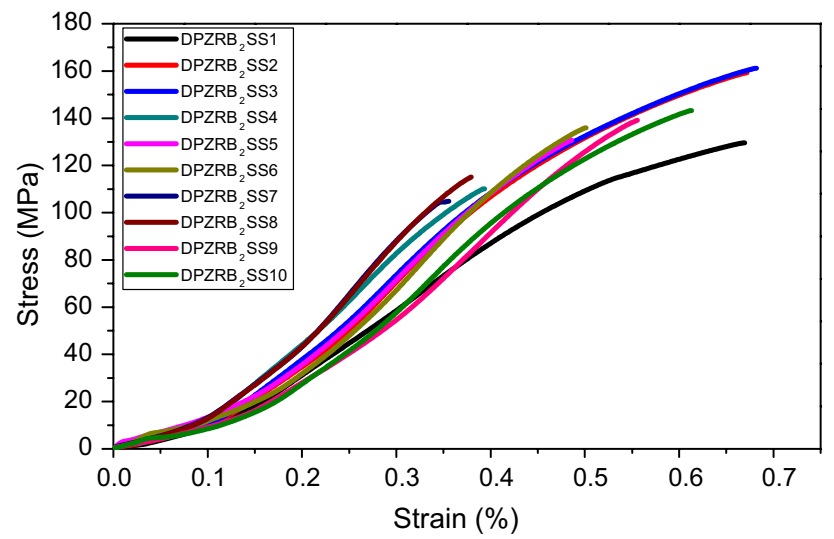

Fig. 2 Stress-strain graph of discarded piston reinforced with zirconium diboride and snail shells

\subsection{Theoretical and experimental hardness with elastic modulus}

It is shown in Table 2 that the experimental hardness was higher than theoretical hardness by a factor of 1.5-2.8. Experimental and theoretical hardness values increase with increase/decrease in wt\% of varying composites as observed in Table 2. Sample DPZRB 2 SS1 ( $80 \mathrm{wt} \%$ of DP, 10 $w t \% Z_{2 R B_{2}}$ and $10 w t \%$ SS) has a lower experimental and theoretical hardness value compared to $\mathrm{DPZRB}_{2} \mathrm{SS} 2(80$ wt $\%$ DP, 20 wt $\% Z Z R B_{2}$ and 0 wt $\%$ SS) with equal amount of $w t \%$ of composites. However, sample DPZRB ${ }_{2} \mathrm{SS} 8$ (70 wt $\%$ $\mathrm{DP}, 30 \mathrm{wt} \% \mathrm{ZRB}_{2}$ and $\left.0 \mathrm{wt} \% \mathrm{SS}\right)$ has a lower experimental hardness to sample DPZRB 2 SS9 (70 wt $\%$ DP, 20 wt $\%$ ZRB $_{2}$ and $10 \mathrm{wt} \% \mathrm{SS}$ ) also at equal amount of wt $\%$ of composites. While sample DPZRB ${ }_{2} \mathrm{SS} 1$ and DPZRB ${ }_{2} \mathrm{SS} 2$ with $20 \mathrm{wt} \%$ of composites have a higher experimental hardness value than sample DPZRB ${ }_{2} \mathrm{SS} 8$ and lower experimental and theoretical hardness to $\mathrm{DPZRB}_{2} \mathrm{SS} 9$ that were reinforced with $30 \mathrm{wt} \%$ of composites. This indicates that the composites improved the hardness of the discarded piston material but there will be a certain wt $\%$ of composite (varying zirconium diboride with snail shells) that will also decrease the hardness of the discarded piston material. It can be generally observed in this study that true hardness is almost two times smaller compared to experimental value [36] because the indentation hardness is denominated by large indentation modulus.

Sakai and Sakai et al. $[15,16]$ reported a significant difference between theoretical hardness value for Vickers, Berkovich and Knop hardness as determined in his work for $\mathrm{Al}_{2} \mathrm{O}_{3}(10,9.5,11 \mathrm{GPa})$ and $\mathrm{Si}_{3} \mathrm{~N}_{4}(12,10,11 \mathrm{GPa})$, compared to theoretical hardness of 36 and $32 \mathrm{GPa}$ in literature. Musil et al. [37] reported mechanical parameters of films with approximately the same hardness and different high value of Young's modulus measured with the diamond indenter of the same load of $20 \mathrm{mN}$, examples are $\mathrm{Zr}-\mathrm{Y}-\mathrm{N}$ film of hardness value of 31.6 and $32.1 \mathrm{GPa}$ with different value of Young's moduli of 229 and 296 GPa likewise for Ti-MO-N with hardness of 43 and 46 GPa with Young's moduli of 413 and $442 \mathrm{GPa}$ under the same diamond indenter load of $20 \mathrm{mN}$.

Firestov et al. $[38,39]$ reported that hardness of a material manufactured by traditional method were usually below E/10 and the use of the "lower" boundary of the theoretical strength was reasonable for estimating the possible ultimate strengthening of these material. However, the experimental result obtained in recent years demonstrated that the measured hardness of a material manufactured by modern technologies can be higher than $\mathrm{E} / 10[38,39]$.

Gibb et al. [40] showed that west indian wood termite with indentation hardness of $1.07 \mathrm{GPa}$ and indentation modulus of 10.5 GPA which gave a true hardness of 17.8 GPa., while, Schoeberl and Jaeger [36] reported that hydrated human enamel has indentation hardness which is thrice as large (3.21 GPa), but its true hardness is almost two times smaller about $10.8 \mathrm{GPa}$ because the indentation hardness is denominated by large indentation modulus of $87.02 \mathrm{GPa}$. This actually complimented the comparison between experimental and theoretical hardness results in this study.

More so, it is evident in Table 2 that theoretical values of Young's modulus were higher than experimental Young's modulus by a factor of 2.4-3.9. Theoretical hardness increases with increase in theoretical modulus as observed in Table 2. It is observed in Table 2 that as the $w t \%$ of zirconium diboride increases, the ratio of hardness to elastic modulus (H/E) in all the samples also increase. This result is in agreement with the work of Zhao et al. [41]. According to Saki [14], he predicted true hardness of $0.40 \mathrm{GPa}$ with elastic modulus of 74.7 $\mathrm{GPa}$ in aluminium compared to the validity of theoretical assumptions for Vicker's hardness of $0.39 \mathrm{GPa}$. The theoretical elastic modulus and theoretical hardness obtained in this study ranges from 64.12 to 92.49 and 15.76-23.29 GPa, respectively, while indentation hardness ranges from 3.34 to $4.87 \mathrm{GPa}$.

The values of theoretical hardness and theoretical elastic modulus obtained in this study is lower to the values reported by Zhao et al. [41] in silicon carbide particle reinforced with aluminium alloy matrix composite. In addition, the calculated (theoretical) values of elastic moduli are slightly larger than the experimental values which is reasonable since the first principle calculation are performed at absolute zero (lowest possible temperature), while the experimental data were measured at room temperature and elastic constants decrease with increasing temperature $[42,43]$. 
Furthermore, having critically studied Table 2 , it was noticed that a significant discrepancies were recorded between experimental and theoretical values of discarded aluminium piston reinforced with zirconium diboride and snail shells. This is similar to discrepancy of $57.6 \%$ between experimental $(38.1 \mathrm{GPa})$ to theoretical $(68.9 \mathrm{GPa})$ value as reported by Nikita et al. and AMS Material Data Sheet [44, 45]. Nikita et al. [44] attributed it to the fact that theoretical Young's modulus was calculated using single crystal, and most accurate accepted values for the sake of sample to ensure the fewest number of grains. However, Nikita et al. [44] used relatively large sample that was most certainly polycrystalline with lot of grains, decreasing the strength relative to pure single crystal metal or ceramics. Nikita et al. [44] reported that any testing of this sort of sample would have a lower modulus than theoretical value.

From Fig. 1, the tensile sample that was used for this experiment is also large which could have resulted to a wide discrepancy between theoretical and experimental Young's modulus. The discrepancies can also be attributed to theoretical elastic moduli which were obtained from perfect/single crystal materials while experimental values were obtained from polycrystalline/imperfect crystals.

Asafa et al.; Katsina and Taiwo $[32,46]$ also reported Young's moduli of 2.6 and $14.44 \mathrm{GPa}$ respectively in their work against literature value of $69 \mathrm{GPa}$ for aluminium. A higher/lower experimental and theoretical value were also reported by Niel [47] who observed that a lower experimental value indicates a decrease in magnitude of the grain boundary strengthening and a higher experimental value could reflect a certain degree of plastic deformation during processing. He also emphasized that for aluminium, where its experimental yield stress is significantly higher than the calculated values. Niel [47] tentatively suggested that the powder might have been slightly oxidized during processing and that the high yield includes a contribution due to oxide dispersion strengthening.

Yuan et al. [48] reported a lower experimental mean Young's moduli of silicon carbide particle and aluminium alloy matrix of $334.7 \mathrm{GPa}$ and $76.8 \mathrm{GP}$, respectively to theoretical value with discrepancy of $25 \%$. It was concluded that for aluminium matrix, the mean Young's moduli were slightly greater than theoretical values. The experimental results of matrix were less than the result of rule of mixture and its effect was attributed to addition of particles [49]. The comparison of the instrumented Young's modulus values and conventional Young's modulus values shows a significant discrepancy. Moreover, difference between theoretical and experimental result of Young's modulus is due to the rule of mixture [49].

Yuan et al. [48] also reported that for comparison with Young's modulus, the mean micro hardness of silicon carbide particle and aluminium alloy matrix is $32.6 \mathrm{GPa}$ and
1.58 GPa. Ayyar et al., Rabiu et al., and Zhang et al. [50-52] concluded that it is necessary to investigate the mechanical behaviour of interface because the experimental and theoretical results of their studies reveal that the failure of the metal matrix composites usually occur at the interface between the particle and the matrix. This is also attributed to the mismatch between particle and matrix; also the extra dislocation adds resistance to deformation during indentation [48].

\subsection{Hardness and elastic modulus}

Experimental modulus and experimental hardness of discarded aluminium piston reinforced with zirconium diboride and snail shell are shown in Table 2. Experimental modulus does not increase with increase in experimental hardness. This indicates that there is a certain wt $\%$ of composite (zirconium diboride varied with snail shells) that will be added to discarded aluminium piston that will increases or decreases the hardness and elastic modulus of the material.

Figure 3 shows theoretical modulus and theoretical hardness graph, it indicates that theoretical modulus increases with increase in theoretical hardness and it has a correlation coefficient of 1 . It can also be inferred from Table 2, that the higher the value of theoretical modulus, the higher the value of theoretical hardness and increase in ratio of hardness to elastic modulus $(\mathrm{H} / \mathrm{E})$, which shows that the mechanical behaviour of aluminium matrix reinforced with zirconium diboride and snail shells also depend on the combination of its hardness $(\mathrm{H})$ and elastic modulus.

This compliments the work of Musil et al., Musil and Vicek, Regent and Musil [53-55] that studied the relationship between hardness and modulus in hard film, which concluded that it can be influenced by the choice its chemical composition and deposition parameters used in its formation. It is also confirmed from Table 2 that resistance to plastic deformation $\left(\mathrm{H}^{3} / \mathrm{E}^{2}\right)$ increases

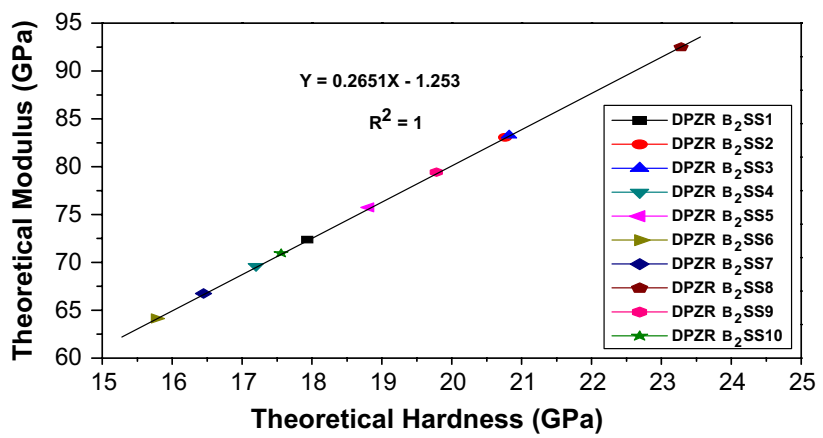

Fig. 3 Theoretical modulus and theoretical hardness graph 
with increase in hardness $(\mathrm{H})$ because the ratio of $\mathrm{H} / \mathrm{E}$ is approximately constant; this supports the work of Musil et al. [37]. It can be generally concluded that the harder the piston material, the higher is modulus of elasticity $(E)$ and the higher is the resistance to plastic deformation.

In addition, the ratio of hardness to modulus (H/E) is approximately constant (0.25) and it shows that deformation properties is less than unity which means it is entirely inelastic [20]. From Table 2, when no snail shell is added in the composite in sample DPZRB ${ }_{2} \mathrm{SS} 2$ and $\mathrm{DPZRB}_{2} \mathrm{SS} 8$, theoretical modulus and hardness were at their peak, which indicates that the wt\% of zirconium diboride in the composite has greater influence than snail shells because of their high modulus of elasticity. This is also evident in sample DPZRB ${ }_{2} \mathrm{SS} 3$ and DPZRB ${ }_{2} \mathrm{SS} 9$ which show high resistance to plastic deformation, modulus of elasticity and hardness are not linearly dependent with wt\% of composite. However, when there was no zirconium diboride in the composite (DPZRB ${ }_{2} \mathrm{SS6}$ ) the experimental and theoretical hardness were not as high as when there was only zirconium in the composite (DPZRB ${ }_{2} \mathrm{SS} 2$ and 8). It was observed in this study that a theoretical and experimental value increases/decreases with wt $\%$ of composite.

\subsection{Chemical composition of the cast discarded aluminium piston and control samples}

Table 3 shows the compositions of the two selected samples using modulus of resilience as the major criteria because it comprises of two mechanical properties (stress and strain). The compositions of the samples are determined using Energy Dispersive (EDXRF) Mini Pal 4, Malvern Pan Analytical, Netherlands. Sample DPZRB ${ }_{2} \mathrm{SS}_{2}$ and $\mathrm{DPZRB}_{2} \mathrm{SS} 3$ consist of $98 \%$ of discarded aluminium alloy. DPZRB 2 SS2 (80 DP, $20 \mathrm{ZRB}_{2}, 0 \mathrm{SS} w \mathrm{wt} \%$ ) has higher aluminium in comparison to $\mathrm{DPZRB}_{2} \mathrm{SS} 3(72.5 \mathrm{wt} \%$ of DP, $22.5 \mathrm{wt} \%$ of $\mathrm{ZRB}_{2}, 5 \mathrm{wt} \%$ of SS) as shown in Table 3. The sample with snail shell particle has a higher proportion of calcium atom. The higher proportion of calcium in the particle can be attributed to the presence of calcium in snail shells in sample DPZRB ${ }_{2} \mathrm{SS}$. This compliments the work of other researchers that used eggshells as a composite $[30,35,56]$.

\subsection{SEM results}

The SEM micrograph/EDS of sample DPZRB ${ }_{2} \mathrm{SS} 2$ (DP +20 $w t \%$ of $Z R B_{2}+0 w t \%$ of SS) and DPZRB ${ }_{2} \mathrm{SS} 3$ (DP $+22.5 \%$ $\mathrm{ZRB}_{2}+5 \% \mathrm{SS}$ wt $\%$ ) are shown in Fig. $4 \mathrm{a}$, $\mathrm{b}$ respectively. Table 4 also shows the EDS composition of DPZRB ${ }_{2} \mathrm{SS}_{2}$ and $\mathrm{DPZRB}_{2} \mathrm{SS}_{3}$. The microstructure shows that the snail shell particles are embedded in the aluminium matrix of sample DPZRB ${ }_{2} \mathrm{SS}_{3}$ as shown in Fig. 4b. Moreso, combination of dimple ductile behaviour of the matrix alloy phase and brittle failure of the reinforcement was observed in samples DPZRB ${ }_{2} \mathrm{SS} 2$ as also reported by Maleque et al. [57]. Particle clustering was noticed in sample DPZRB ${ }_{2} \mathrm{SS}_{3}$ which may have occurred due to the insufficient stirring speed and time. Agida et al. [58] reported that clustered reinforcement particles hindered the uniform distribution of particles, as a result of the porosity level elevated in the region and causes deterioration of mechanical properties. The melting of discarded aluminium piston was carried out at optimum temperature of $700 \pm 5{ }^{\circ} \mathrm{C}$ for proper viscosity to be achieved which provides better distribution of the particles.

In addition, while adding zirconium diboride and snail shells to discarded aluminium piston, the temperature of the whole mixture was raised to $1300^{\circ} \mathrm{C}$ for uniform distribution of the reinforcement. It can be seen from Fig. $4 \mathrm{a}$ that zirconium diboride particles are uniformly distributed in the aluminium matrix as zirconium diboride particles exhibit spherical shape. Naveen et al. [59] concluded that the shape, size and spatial distribution of zirconium diboride particles influence the mechanical properties of the composite to a large extent; this was also observed in their mechanical properties as shown in Table 2. Naveen et al. [59] reported that average reinforcement particles size increased with wt\% of reinforcement particles and the coarsening of particle was due to high reaction rate.

Fogagnolo et al. [60] reported that the higher the reinforcement contents, the higher the possibility of clusters and defects. A little pore was observed which may be due to improper compaction or particles pull out during grinding and polishing. It may also be attributed to the dissolved gases and air bubbles sucked into the melt while adding the zirconium and snail shells powder to the molten aluminium (ingot). Ramesh et al. [61] reported that high hardness is always associated with lower porosity of MMCs which is

Table 3 Composition of discarded aluminum piston reinforced with zirconium diboride and snail shells

\begin{tabular}{llllllllllllll}
\hline Elements & $\mathrm{Si}$ & $\mathrm{Al}$ & $\mathrm{Ca}$ & $\mathrm{Ti}$ & $\mathrm{Mn}$ & $\mathrm{Fe}$ & $\mathrm{Cu}$ & $\mathrm{Zn}$ & $\mathrm{V}$ & $\mathrm{Cr}$ & $\mathrm{Sb}$ & $\mathrm{As}$ & $\mathrm{Pb}$ \\
\hline DPZRB $_{2} \mathrm{SS} 2$ & 0.27 & 98.70 & 0.023 & 0.027 & 0.100 & 0.320 & 0.699 & 0.115 & 0.002 & 0.0035 & 0.044 & $\mathrm{ND}$ & 0.018 \\
DPZRB $_{2} \mathrm{SS3}$ & 0.32 & 98.51 & 0.041 & 0.026 & 0.106 & 0.322 & 0.735 & 0.122 & 0.001 & 0.0053 & 0.073 & 0.0006 & 0.017 \\
\hline
\end{tabular}



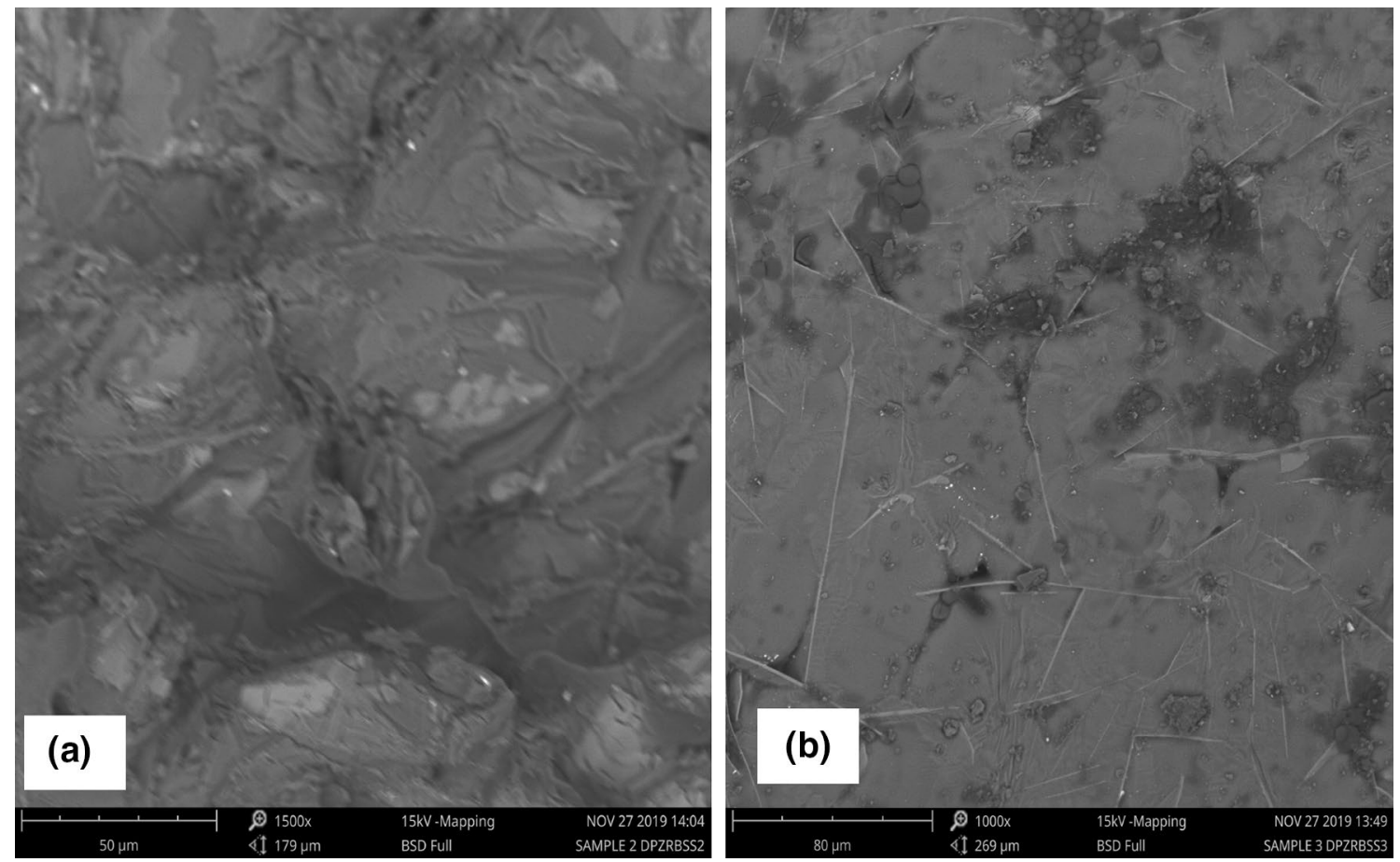

Fig. 4 SEM Micrograph/EDX of: a discarded piston $+20 \% \mathrm{ZRB}_{2}+0 \%$ snail shell at $\times 2000\left(\mathrm{DPZRB}_{2} \mathrm{SS}_{2}\right) ; \mathbf{b}$ discarded piston $+22.5 \% \mathrm{ZRB} \mathrm{B}_{2}+5 \%$ snail shell at $\times 2000\left(D^{2} Z R B_{2} S S 3\right)$

Table 4 EDX composition of sample DPZRB ${ }_{2} \mathrm{SS} 2$ and $\mathrm{DPZRB}_{2} \mathrm{SS} 3$

\begin{tabular}{|c|c|c|c|c|c|c|c|}
\hline \multirow[t]{2}{*}{ S. no. } & \multirow[t]{2}{*}{ Element no. } & \multirow[t]{2}{*}{ Element name } & \multirow{2}{*}{$\begin{array}{l}\text { Element } \\
\text { symbol }\end{array}$} & \multicolumn{2}{|l|}{$\mathrm{DPZRB}_{2} \mathrm{SS} 2$} & \multicolumn{2}{|l|}{$\mathrm{DPZRB}_{2} \mathrm{SS} 3$} \\
\hline & & & & $\begin{array}{l}\text { Atomic } \\
\text { concentra- } \\
\text { tion }\end{array}$ & $\begin{array}{l}\text { Weight } \\
\text { concentra- } \\
\text { tion }\end{array}$ & $\begin{array}{l}\text { Atomic } \\
\text { concentra- } \\
\text { tion }\end{array}$ & $\begin{array}{l}\text { Weight } \\
\text { concentra- } \\
\text { tion }\end{array}$ \\
\hline 1 & 13 & Aluminium & Al & 41.59 & 46.77 & 43.23 & 53.27 \\
\hline 2 & 14 & Silicon & $\mathrm{Si}$ & 17.26 & 20.20 & 17.13 & 21.96 \\
\hline 3 & 5 & Boron & B & 24.90 & 11.22 & 19.22 & 9.49 \\
\hline 4 & 26 & Iron & $\mathrm{Fe}$ & 3.96 & 9.21 & 0.51 & 1.30 \\
\hline 5 & 6 & Carbon & $\mathrm{C}$ & 7.97 & 3.99 & 17.85 & 9.79 \\
\hline 6 & 47 & Silver & $\mathrm{Ag}$ & 0.58 & 2.62 & - & - \\
\hline 7 & 19 & Potassium & K & 0.85 & 1.38 & 0.23 & 0.41 \\
\hline 8 & 40 & Zirconium & $\mathrm{Zr}$ & 0.33 & 1.24 & 0.29 & 1.20 \\
\hline 9 & 20 & Calcium & $\mathrm{Ca}$ & 0.62 & 1.03 & 0.18 & 0.33 \\
\hline 10 & 16 & Sulfur & $\mathrm{S}$ & 0.62 & 0.83 & 0.37 & 0.55 \\
\hline 11 & 11 & Sodium & $\mathrm{Na}$ & 0.54 & 0.52 & 0.20 & 0.21 \\
\hline 12 & 12 & Magnesium & $\mathrm{Mg}$ & 0.49 & 0.50 & 0.40 & 0.45 \\
\hline 13 & 22 & Titanium & $\mathrm{Ti}$ & 0.16 & 0.32 & 0.06 & 0.14 \\
\hline 14 & 15 & Phosphorus & $P$ & 0.13 & 0.17 & - & - \\
\hline 15 & 30 & Zinc & $\mathrm{Zn}$ & - & - & 0.21 & 0.62 \\
\hline 16 & 25 & Manganese & $\mathrm{Mn}$ & - & - & 0.11 & 0.29 \\
\hline
\end{tabular}

\subsection{XRD analysis}

graph was observed in the two samples due to special bonding system of zirconium diboride as reported by the authors [8-11].
The XRD analysis of discarded aluminium piston reinforced with zirconium diboride and snail shells is shown 
in Fig. 5. Sample DPZRB ${ }_{2} \mathrm{SS} 2\left(\mathrm{DP}+20 \mathrm{wt} \% \mathrm{ZRB}_{2}+0 \mathrm{wt} \%\right.$ SS) and $\mathrm{DPZRB}_{2} \mathrm{SS} 3\left(\mathrm{DP}+22.5 \mathrm{wt} \% \mathrm{ZRB}_{2}+5 \mathrm{wt} \% \mathrm{SS}\right)$ are the two samples selected from Table 2 for further characterization. Zirconium diboride (dissolved), calcium, aluminium, graphite and bromine are found at the peak of the samples as revealed by XRD. Samples DPZRB ${ }_{2} \mathrm{SS} 2$ contain aluminium, calcium, zirconium bromide (dissolved zirconium diboride), iron zirconium and calcium bromide (Al, $\mathrm{Ca}, \mathrm{ZRB}_{2}, \mathrm{ZRFe}_{2}, \mathrm{CaBr}_{2}$ ) as revealed by face-centered cubic (fcc), hexagonal closest packed (hcp) and body-centered cubic (bcc) peaks of the XRD while; sample 3 contains aluminum, zirconium and graphite (Al, ZR, C).

The intensity of sample DPZRB ${ }_{2} \mathrm{SS} 3$ is higher than that of DPZRB ${ }_{2} \mathrm{SS} 2$ as shown in Fig. 5 . It can be observed that carbon is present in sample 3 , while calcium is present in sample 2 as shown by XRD. Zirconium bromide from zirconium diboride is only revealed in sample 2 by XRD but present as zirconium diboride in sample 3 . Zirconium diboride has excellent mechanical properties with higher strength and fracture toughness while graphite being a crystalline form of carbon has high hardness and good shield properties against neutron. Durowoju et al. and Narendremath et al. $[62,63]$ concluded that graphite has high thermal conductivity, low coefficient of thermal expansion and low density. Graphite has a wettability problem which may occur between the metal and graphite interface but low

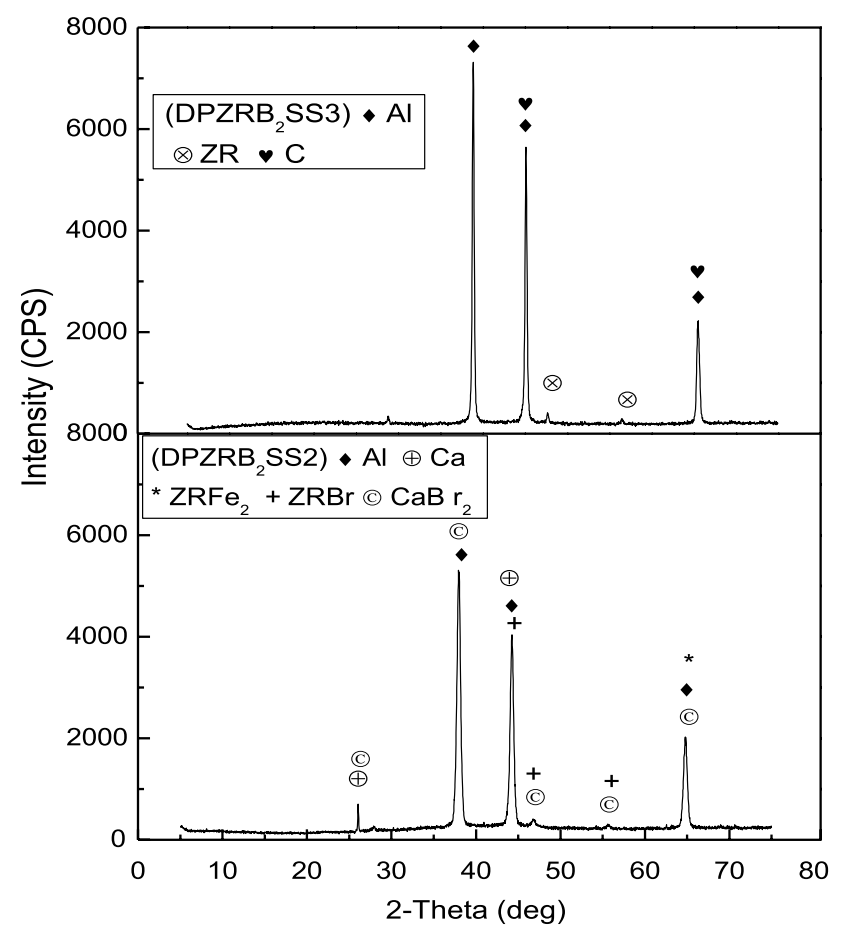

Fig. 5 XRD pattern of discarded piston reinforced with zirconium diboride and snail shells (DPZRB $\mathrm{SS}_{2}$ and $\mathrm{DPZRB}_{2} \mathrm{SS}_{3}$ ) melting point metals are used to solve this problem which makes graphite find its applications in piston production.

The $d$-spacing of each peak was obtained by using Bragg equation. The peaks obtained from this analysis were matched with the minerals phases of the $d$ (Theta in deg). At $2 \theta=38.75^{\circ}$ the particle size of crystalline $(\mathrm{nm})$ of sample $2\left(\mathrm{Al}, \mathrm{CaBr}_{2}\right)$ and $3(\mathrm{Al})$ are 4.28 and $5.61 \mathrm{~nm}$ respectively, while at 2-Theta ( $45 \mathrm{deg})$ the particle size of sample 2 and $3(\mathrm{Al}, \mathrm{C})$ are 4.28 and $5.74 \mathrm{~nm}$. In addition, the particle size of sample 2 ( $\mathrm{Al}, \mathrm{CaBr}_{2}, \mathrm{ZRFe}_{2}$ ) and sample 3 ( $\mathrm{Al}$, C) at 65 degrees are 4.69 and $6.29 \mathrm{~nm}$ respectively. It was shown in Table 2 (DPZRB $\left.{ }_{2} \mathrm{SS}_{3}\right)$ that zirconium diboride and snail shell improved the hardness of the sample compared to other samples and the peak intensity ratio of sample $\mathrm{DPZRB}_{2} \mathrm{SS} 3$ is seen to be higher than $\mathrm{DPZRB}_{2} \mathrm{SS} 2$ due to the presence of snail shells.

The particle sizes were distributed in the range of 3.06-17.90 nm for $\mathrm{DPZRB}_{2} \mathrm{SS} 2$ with average particle size of $7.03 \mathrm{~nm}$ while DPZRB $\mathrm{SS}_{3}$ particle sizes were distributed in the ranges of 5.6-9.03 nm with average particle size of $7.07 \mathrm{~nm}$. It will be important to note that the melting temperature of zirconium diboride is higher than the melting temperature of discarded aluminium piston $\left(700^{\circ} \mathrm{C}\right)$ which is the matrix metal. Snail shells which serve as one of the composite melt at $60^{\circ} \mathrm{C}$ and will dissolve in the mixture of discarded piston and composite (zirconium diboride and snail shells) when the temperature of the mixture was raised to $1300^{\circ} \mathrm{C}$ and stirred.

In summary, the strengthening mechanism of discarded aluminium piston reinforced with zirconium diboride and snail shells played a major role and it is attributed to load transfer mechanism, dislocation mechanism and fine grain strengthening. The high strength particle/matrix interface can transfer maximum load to the particle until the particle fracture occurs. Moreso, the relationship between the particle strength and particle matrix interface strength determine the tensile strength of the composite [27]. Zirconium diboride acts as load bearing element and take maximum load for plastic deformation by increasing the hardness [28]. While, snail shells particle was reported to be effective in distributing the applied stress over a large volume at the base of the notch, and which helped to prevent propagation of cracks by carrying large part of the load in the area under crack [29].

\section{Conclusions}

The D-optimality technique was used for optimization and to determine the mixing composition of the cast sample. Despite the fact that a lower experimental Young's modulus values were obtained, the stress- strain curve from 
which they are obtained from still conform to the expected profile and mechanics of metals.

The theoretical hardness was determined from the ratio of indentation hardness to indentation modulus, while the elastic modulus was found by composite compositions which were analyzed by composite equation.

It was observed that as theoretical and experimental hardness and Young's modulus increases/decreases with increase in wt\% of composite. This suggests that stress transfer across the aluminium particle interface.

A well bonded micrograph was also observed due to special bonding system of zirconium diboride and its excellent mechanical properties.

\section{Compliance with ethical standards}

Conflict of interest On behalf of all authors, the corresponding author states that there is no conflict of interest.

\section{References}

1. Davis JR, Joseph R (1993) Aluminium and aluminium alloys. ASM specialty handbook. ASM International, Cleveland

2. Totten GE, Mackenzie DS (2003) Handbook of aluminium, vol 1. Marcel Dekker, New York, pp 579-700

3. Veeresh GB, Rao CSP, Selvaraj N (2011) Mechanical and tribological behaviour of particulate reinforced aluminium metal composite-a review. J Miner Mater Charact Eng 10(1):55-91

4. Sudarshan-Surappa MK (2008) Synthesis of fly ash particle reinforced A356. Aluminium composite and their characterization. Mater Sci Eng A 480:117-124

5. Ravesh SK, Garg TK (2012) Preparation and analysis for some mechanical property of aluminium based matrix composite reinforced with SiC and fly-ash. Int J Eng Res Appl 2(6):727-731

6. Ramesh CS, Anwar-Khan AR, Ravikumar N, Savanprabhu P (2005) Prediction of wear coefficient of $\mathrm{Al}_{6061-\mathrm{TiO}_{2}}$ composite. Wear 259:602-608

7. Dipti KD, Puma CM, Saranjit S, Ratish KT (2014) Properties of ceramics reinforced aluminium matrix composites (review). Int J Mech Mater Eng 1:12

8. Fahrentholz WG, Hilmas GE, Talmy IG, Zaykoski JA (2007) Refractory diborides of zirconium and halfnium. J Am Ceram Soc 90(5):1347

9. Vajeesten P, Ravindran P, Ravi C, Asokamani R (2001) Electronic structure bonding and ground state properties of $A^{2} B_{2}$-type transition metal diborides. Phys Rev B 63(4):045115

10. Shvoeikin GP (1994) The chemical bonding and electron properties of metal borides. Russ Chem Rev 63(9):711-734

11. Burdett JK, Canadell E, Miller GJ (1986) Electronic structure of transition metal borides with the $\mathrm{ALB}_{2}$ structure. J Am Chem Soc 108(21):6561

12. Jato EO, Asia IO, Egbon EE, Otutu JO, Chukwuedo MO, Ewansiha CJ (2010) Treatment of waste water from food industry using snail shell. Acad Arena 2:32-36

13. Haque MM (1998) Effect of process variables on structure and properties of aluminium silicon piston alloy. J Mater Process Technol 77:122-128
14. Sakai M (1993) Energy principle of the indentation-induced inelastic surface deformation and hardness of brittle materials. Acta Metall Mater 41(6):1751-1758

15. Sakai M (1999) The meyer hardness; a measure for plasticity. J Mater Res 14(09):3630-3639

16. Sakai M, Shimuzu S, Ishikawa T (1999) The indentation loaddepth curve of ceramics. J Mater Res 14:1471

17. Cheng YT, Cheng CM (1998) Relationship between hardness, elastic modulus and work of indentation. Appl Phys Lett 73:614. https://doi.org/10.1063/121873

18. Labonte D, Lenz AK, Oyen ML (2017) On the relationship between indentation hardness and modulus, and the damage resistance of biological materials. Acta Biomater 57:373-383. https://doi.org/10.1016/j.actbio.2017.05.034

19. Haines J, Leger JM, Bocquillon G (2001) Synthetic and design of superhard materials. Annu Rev Mater Res 31:1-23. https://doi. org/10.1146/annurev.matsci.31.1.1

20. Williams JA (1994) Engineering tribology. Oxford University Press, Oxford

21. Olawuni EO, Durowoju MO, Asafa TB, Mudashiru LO (2018) Development of piston materials from discarded aluminum piston alloyed with zirconium diboride and snailshells. Int J Adv Sci Eng 51:818-828

22. Prakash G, Arun LR (2013) Characterisation of aluminum flyashalumina composite for piston analysis by CAE tools. Int J Innov Res Sci Eng Technol 2(12):2319-8753

23. Callister WD (2007) An introduction, material science and engineering, 7th edn. Department of Metallurgical Engineering, The University of Utah, Salt Lake City. ISBN 978-0-471-73696-7

24. Gumus RH, Okpeku I (2015) production of activated carbon and characterization from snail shell waste (Helix pomatia). Adv Chem Eng Sci 5:51-61. https://doi.org/10.4236/aces.2015.51006

25. www.amesweb.info/material

26. www.reade.com/product-zirconium-diboride-zirconium-borid e-Zrb2

27. Shen YL, Williams JJ, Piotrowski G (2001) Correlation between tensile and indentation behaviour of particle-reinforced metal matrix composite: an experimental and numerical study. Acta Mater 49:3219-3229

28. Dinaharan I, Murugan N, Siva P (2011) Influence of in-situ formed $\mathrm{ZrB}_{2}$ particle on microstructure and mechanical properties of AA6061 metal matrix composite. Mater Sci Eng A 528:5733-5740

29. Genevive C, Onuegbu I, Ogbennaya I (2011) The effects of filler contents and particle sizes on the mechanical and end-use properties of snail shell powder filled polypropylene. Mater Sci Appl 2:811-817

30. Hussein AA, Salim RD, Sultan AA (2011) Water absorption and mechanical properties of high density polyethylene/eggshell composite. J Basrah Res (Sci) 37:36-42

31. Atuanya CU, Aigbodion VS, Obiorah SO, Kchaou M, Elleuch R (2015) Empirical model for estimating the mechanical and morphological properties of recycled low density polyethylene/snail shell bio-composites. J Assoc Arab Univ Basic Appl Sci. https:// doi.org/10.1016/j.jaubas.2015.01.001

32. Asafa TB, Durowoju MO, Oyewole AA, Solomon SO, Adegoke RM, Aremu OJ (2015) Potentials of snail shells as reinforcement for discarded aluminum based materials. Int J Adv Sci Technol $84: 1-8$

33. Aigbodion VS, Hassan SB (2007) Effect of silicon carbide reinforcement on microstructure and properties of cast Al-Si-Fe/ $\mathrm{SiC}$ particulate composites. J Mater Sci Eng A 447:355-360

34. Durowoju MO, Babatunde IA (2014) Effect of antimony on the tensile strength and the morphology of si platelets in recycled aluminium piston alloys. J Mater Sci Eng 3:137 
35. Patrici T, Quijad RL, Yazdani-Pedram JL, Arias M (2007) Eggshell a new bio filler for polypropylene composite. Mater Lett 61(22):4347-4350

36. Schoeberl T, Jaeger IL (2006) Wet or dry-hardness stiffness and wear resistance of biological material on the micron scale. Adv Eng Mater 8(11):1164-1169

37. Musil J, Kunc F, Zeman H, Polakova H (2002) Relationship between hardness, Young's modulus and elastic recovery in hard nano composite coating. Surf Coat Technol 154:304-313

38. Firstov SA, Gorban VF, Pechkovskii EP (2007) Relationship between the strength characteristic of materials and the automatic indentation parameters. Materialoved 11:26-31

39. Firstov SA, Rogul TG, Gorban VF (2009) Ultimate strengthening, theoretical and limit tool hardness. Key Eng Mater 409:128-136

40. Gibb BW, Stewart A, Huang H, Truss R, Woller B, Rasch R, Zalucki MP (2008) Insect mandibles-comparative mechanical properties and links with metal incorporation. Naturwissen-chaften 95(1):17-23

41. Zhao MJ, Liu Y, Bi J (2005) Correlation between tensile strength, elastic modulus and macrohardness in silicon carbide particle reinforced aluminium alloy matrix composite. Mater Sci Technol 4:429

42. Ledbetter H (1994) Relationship between bulk modulus temperature dependence and thermal expansivity. Phys Status Solidi B Basic Res 181:81-85. https://doi.org/10.1002/pssb.2221810109

43. Wang J, Du Y, Shang SL, Liu ZK, Li YW (2014) Effects of alloying elements on elastic properties of Al by first principle calculations. J Min Metall 50(1):37-44

44. Nikita K, Daniel L, Keisuke M, Jennie Z (2013) Uniaxial tension and compression testing of materials. 3.032 Laboratory report

45. AMS Material Data Sheets. www.matweb.com

46. Katsina CB, Taiwo AA (2016) Effect of different melting practices on mechanical properties of sand cast Al-Si alloy scraps. Leonardo J Sci 29:113-124

47. Niels $\mathrm{H}$ (2004) Hall-Petch relation and boundary strengthening. Scr Mater 51:801-806

48. Yuan Z, Li F, Zhang P, Chen B, Xue F (2014) Mechanical properties study of particles reinforced aluminium matrix composite by micro-indentation experiment. Chin J Aeronaut 27(2):397-406

49. Mussert K, Vellinga WP, Bakker A, Van Der Zwaag SA (2002) Nanoindentation study on the mechanical behaviour of the matrix material in an AA6061- $\mathrm{Al}_{2} \mathrm{O}_{3}$ MMC. J Mater Sci 37(4):789-794

50. Ayyar A, Chawla N (2007) Microstructure based modeling of the influence of particle spatial distribution and fracture on crack growth in particle reinforced composite. Acta Mater 55(18):6064-6073

51. Rabiu A, Vendra L, Kishi T (2008) Fracture behaviour of particle reinforced metal matrix composite. Composites A 39(2):294-300
52. Zhang T, Wang Y, Zhou Y, Song G (2009) Effect of particle clustering of the effective modulus of $\mathrm{ZrC} / \mathrm{W}$ composite. Int J Refract Met Hard Mater 27(1):14-19

53. Musil J, Karvankova P, Kasl J (2000) Hard and super hard Zr-Ni-N nano composite film. Surf Coat Technol 139:101-109

54. Musil J, Vicek J (2001) Magnetron sputtering of hard nano composite coatings and their properties. Surf Coat Technol 142-144:557-566

55. Regent F, Musil J (2001) Magnetron sputtered Cr-Ni-N and TiMo-Si-N films: comparism of mechanical properties. Surf Coat Technol 142-144:146-157. https://doi.org/10.1016/s0257 -8972(01)01250-6

56. Patricio T, Raul Q, Mehredad YP, Jose LA (2007) Eggshell, a new bio filler for polypropylene composite. Mater Lett 61:567-572

57. Maleque MA, Adebisi A, Izzati A (2016) Analysis of fracture mechanism for Al-Mg/SiCp composite materials. In: International conference on mechanical, automotive and aerospace engineering: material science and engineering

58. Agida SN, Ghazal MI, Hashim J (2004) Effect of porosity on mechanical properties of metal matrix composite: an overview. J Technol A 40A:17-32

59. Naveen G, Narayanasamy R, Natarajan S, Kumaresh SP, Sivaprasad K, Sivasankaran S (2010) Dry sliding wear behavoiur of $A A 6351-\mathrm{ZrB}_{2}$ in-situ composite at room temperature. Mater Des 31:1526-1532

60. Fogagnolo JB, Robert MH, Ruiz-Navas EM, Torralbi JM (2004) 6061 Al reinforced with zirconium diboride particles processed by conventional powder metallurgy and mechanical alloying. $J$ Mater Sci 39:127

61. Ramesh CS, Keshavamurthy R, Channabasappa BH, Abrar A (2008) Microstructure and mechanical properties of $\mathrm{Ni}-\mathrm{P}$ coated $\mathrm{Si}_{3} \mathrm{~N}_{4}$ reinforced Al6061 composites. Mater Sci Eng A 502:99-106

62. Durowoju MO, Sadiku ER, Diouf S, Shongwe MB, Olubanbi PA, Mekgwe N, Ramakokovhu MR (2016) Effect of micron and nanosized $\mathrm{ZrB}_{2}$ addition on microstructure and properties of spark plasma sintered graphite-aluminium hybrid composite. J Mater Sci Mater Electron. https://doi.org/10.1007/s10854-016-4346-3

63. Narendremath CS, Rohatgi PK, Yegneswarah AR (1986) Observation of graphite structure under optical and scanning electron microscope. J Mater Sci 5(6):592-594

Publisher's Note Springer Nature remains neutral with regard to jurisdictional claims in published maps and institutional affiliations. 